\title{
Profissão
}

\section{Actor / Actriz}

Ana Campos

\section{Vera Borges, Teatro, prazer e risco: Retratos sociológicos de actores e encenadores portugueses, Lisboa, Roma Editora, 2008, col. Evolução, 178 pp.}

Depois da publicação em 2007 de 0 Mundo do teatro em Portugal: Profissão de actor, organizações e mercado de trabalho, obra que resulta da sua tese de doutoramento em Sociologia na École des Hautes Études en Sciences Sociales de Paris e na Universidade Nova de Lisboa, Vera Borges publica Teatro, prazer e risco dando a conhecer mais material relevante sobre o teatro enquanto meio profissional.

Enquanto, na primeira das obras referidas, a autora se debruça sobre o teatro na globalidade, analisando, a partir do estudo de casos, a organização das companhias e seu funcionamento interno como entidades empregadoras que visam a obtenção de lucros e simultaneamente a criação artística, na obra em análise a autora apresenta as condições de trabalho de actores e encenadores na actualidade a partir do estudo de dez companhias em concreto. 0 livro apresenta a biografia profissional de elementos das companhias 0 Bando, A Cornucópia, Teatro da Garagem, As Boas Raparigas, 0 Olho, Teatro de Marionetas do Porto, Teatro Regional da Serra de Montemuro, Pogo Teatro, Artistas Unidos e Depois da Uma com o objectivo de, partindo das respostas às perguntas que formulou, delinear os traços da profissão do actor e do encenador na actualidade.

\footnotetext{
As respostas dos actores e dos encenadores a estas perguntas permitem-me descrever as suas formas de entrada no teatro e as suas modalidades de socialização profissional, as caracteristicas regulares do engagement dos actores nos grupos, a evolução do mercado de trabalho teatral português e as formas de construção da identidade colectiva deste grupo profissional. (p. 13)
}

Este estudo parte do pressuposto de que tanto os actores como os encenadores e os próprios grupos caminham para uma profissionalização cada vez mais

Ana Campos é Mestre em Estudos de Teatro, professora do Ensino

Secundário

investigadora do Centro de Estudos de Teatro da Faculdade de Letras da Universidade de Lisboa. explícita, o que implica sérias transformações no meio teatral português, situação que este trabalho pretende identificar.

Para além da análise de alguns elementos das companhias referidas, a autora procurou também defini a relação entre as diversas companhias, a visão de teatro predominante em cada uma delas e o modo como os actores que ai trabalham gerem as suas carreiras. Nas propostas de discussão lançadas pela obra, a autora, que

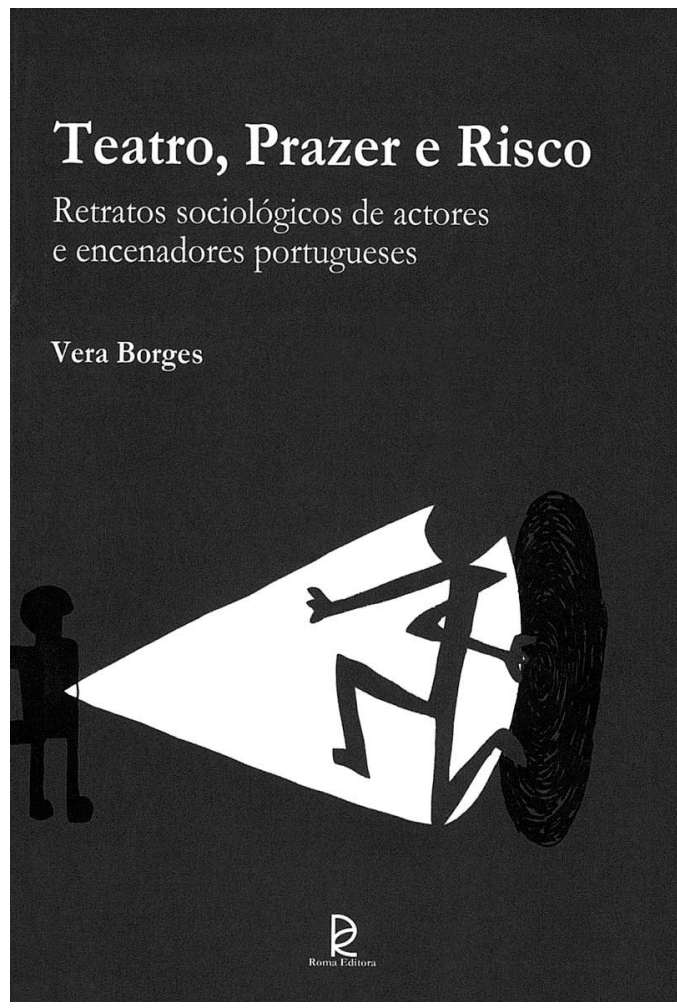

ao longo do seu estudo dividiu os entrevistados em "geração antiga", "geração intermédia" e "nova geração", constata que enquanto os mais antigos entraram no meio com pouca ou nenhuma formação curricular de base e se profissionalizaram dentro das companhias a que pertencem - o que Ihes condiciona bastante a possibilidade de encontrarem emprego fora delas -, a geração intermédia e a mais nova entraram no meio teatral através de uma longa formação inicial. No entanto, esta nova geração trabalha de um modo geral como freelance, saltando de companhia em companhia consoante os projectos que Ihe surgem, o que é simultaneamente um factor de instabilidade, mas também um motor de desenvolvimento. Nesta tentativa de sobreviver dentro de condições laborais tão precárias, é prática comum um actor trabalhar vários anos como convidado numa companhia e ser pago a recibos verdes. De resto, muitos actores reclamam eles próprios o direito de, mesmo que ligados a uma companhia específica, poderem abarcar outros projectos fora delas. Esta situação cria hábitos que os mais antigos consideravam inimagináveis no início das suas carreiras, como actores a ensaiarem sozinhos - para conciliarem o tempo de 
ensaio com outros projectos -, ou a estarem presentes apenas nas cenas em que entram ou ainda a limitarem a sua presença a um horário de trabalho previamente estabelecido. 0 director d' A Cornucópia por exemplo lamenta a perda do espírito de dedicação e sacrificio ao teatro que distinguia a sua geração.

A capacidade de adaptação dos mais novos às diferentes companhias por onde vão passando e a sua necessidade de aceitar outros trabalhos como a publicidade, a televisão ou o cinema, na maior parte dos casos inacessiveis aos actores mais antigos, não os faz subestimar os seus colegas de profissão. De facto, os mais novos procuram o aprendizado junto de companhias estabelecidas e de actores e encenadores consagrados. Dentro do meio teatral, onde tudo ou quase tudo se processa ainda pelas relações pessoais que se estabelecem, o renome de um actor é dado pelo prestígio das companhias e encenadores com que trabalhou. A situação é levada ao limite quando novas pequenas companhias, espaços de liberdade criativa onde os seus fundadores procuram a experimentação, só subsistem enquanto satélites de companhias estabelecidas: é o caso de o Útero em relação a 0 Bando e de Depois da Uma em relação aos Artistas Unidos. Este tipo de relações beneficia os pequenos grupos porque thes fornecem condições logísticas, a publicidade, e a possibilidade de apresentação dos seus trabalhos, dando aos grupos-mãe o benefício de diversificarem a sua programação.

As gerações mais novas vão mais longe falando numa escola d' 0 Bando ou numa escola d' A Cornucópia.

Da análise da evolução das companhias mais antigas, a investigadora concluiu que se passou de uma situação nos anos setenta (data da sua fundação) - em que todos recebiam o mesmo e faziam tudo o que fosse preciso dentro da companhia - para uma cada vez maior especialização e diversificação de tarefas. Estas companhias mais velhas encontram-se ainda hoje presas a uma estética na maior parte dos casos determinada pela figura-chave do seu encenador, enquanto os mais novos procuram grupos sem encenador, optando por um director artístico, funcionando na base da liberdade criativa de cada um, a que a autora chama "todos ao palco!", nome aliás da sua primeira obra, publicada em 2001. Nas companhias mais antigas estudadas, esta nova lógica é sentida de diferentes modos. Se, por um lado, em grupos como o da Cornucópia, que dedica muito tempo ao trabalho sobre o texto, as pressões de rapidez na estreia dos espectáculos e a pouca disponibilidade dos actores mais jovens, que mantêm outras ocupações, é considerado como pondo em causa o futuro daquela forma de fazer teatro, n' 0 Bando, por exemplo, procura-se a renovação das suas práticas através da contratação de especialistas em diferentes áreas que propõem novos modos de fazer as coisas.

Independentemente das soluções encontradas, as gerações mais antigas sentem uma enorme falta de projecto artístico, de uma concepção estética própria, nos actores mais novos e nos projectos que criam, uma ausência de ideologia que caracterizava as companhias fundadas na década de setenta. 0 entrevistado designado como encenador convidado de As Boas Raparigas sublinha que, para além da formação inicial, os actores precisam de modelos, exemplos, pelos quais se rejam. Há companhias no entanto, como os Artistas Unidos, que, embora recente, é dirigida por um dos fundadores d' A Cornucópia, que opta por fazer gravitar em torno de um encenador consagrado um grande número de jovens actores trabalhando todos num claro processo de aprendizagem intergeracional.

Na geração intermédia encontram-se semelhanças na forma de entrada no meio teatral. Quase todos os entrevistados nesta faixa etária entraram no meio através da escola onde estabeleceram relações pessoais que thes permitiram depois a profissionalização. Vera Borges conclui mesmo que é bastante fácil entrar no meio comparativamente com a dificuldade enorme que é subsistir activamente dentro dele. Esta geração procura de um modo geral formas underground de teatro que entretanto, segundo crê a autora, se terão esgotado.

Os percursos mais singulares entre os entrevistados encontram-se dentro das companhias de teatro especializado como o Teatro Regional da Serra de Montemuro e a companhia de Teatro de Marionetas do Porto. Ai encontramos elementos que entraram muito cedo no meio teatral, começando a sua formação na adolescência e ainda elementos que se formaram dentro dos grupos nunca tendo estudado para além do ensino básico.

A crescente especialização, aquilo a que autora chama o freelancismo, a instabilidade e insegurança profissional, que caracterizam as condições de trabalho dos mais jovens, não são, todavia, uma especificidade do meio teatral: são apenas o reflexo do estado actual do mercado de trabalho. Acontece, porém, que, dentro do teatro se assiste a um aumento da criação de auto-emprego com os actores a imaginarem os seus próprios projectos que depois tentam vender, criando assim o seu próprio emprego e reconvertendo-se dentro da carreira.

Embora esta análise sociológica do teatro seja muito interessante para os estudiosos e profissionais do meio, seria muito proveitoso que a obra publicada se desligasse, de alguma forma, dos condicionalismos académicos para se tornar numa fonte de informação mais útil ao leitor. Refiro-me concretamente à opção metodológica por substituir o nome dos entrevistados por um código que, ao leitor nada diz e nada interessa. Também me parece desequilibrado o peso dado aos retratos sociológicos em comparação com a reflexão sobre os mesmos, essa sim particularmente interessante e plena de pistas de trabalho. 